Corrigendum

\title{
Corrigendum to "On Synergistic Integration of Adaptive Dithering Based Internal Model Control for Hysteresis Compensation in Piezoactuated Nanopositioner"
}

\author{
Saikat Kumar Shome, ${ }^{1}$ Mangal Prakash, ${ }^{2}$ Sourav Pradhan, ${ }^{2}$ and Arpita Mukherjee ${ }^{1}$ \\ ${ }^{1}$ Academy of Scientific and Innovative Research (AcSIR), CSIR Central Mechanical Engineering Research Institute \\ (CSIR-CMERI) Campus, Durgapur, India \\ ${ }^{2}$ Department of Electrical Engineering, University of Minnesota, Minneapolis, MN 55455, USA
}

Correspondence should be addressed to Saikat Kumar Shome; saikatkumarshome@gmail.com

Received 9 February 2017; Accepted 1 March 2017; Published 9 April 2017

Copyright (c) 2017 Saikat Kumar Shome et al. This is an open access article distributed under the Creative Commons Attribution License, which permits unrestricted use, distribution, and reproduction in any medium, provided the original work is properly cited.

In the article titled "On Synergistic Integration of Adaptive Dithering Based Internal Model Control for Hysteresis Compensation in Piezoactuated Nanopositioner" [1], the affiliation of the first and fourth authors was incomplete. The correct affiliation is shown above.

\section{References}

[1] S. K. Shome, M. Prakash, S. Pradhan, and A. Mukherjee, "On synergistic integration of adaptive dithering based internal model control for hysteresis compensation in piezoactuated nanopositioner," Mathematical Problems in Engineering, vol. 2015, Article ID 365141, 19 pages, 2015. 


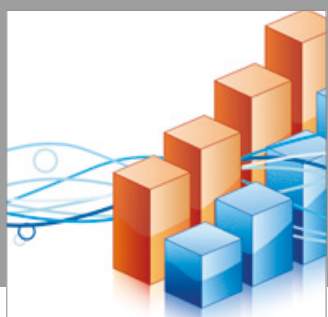

Advances in

Operations Research

vatersals

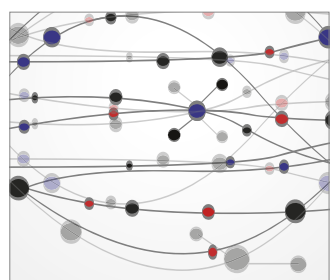

\section{The Scientific} World Journal
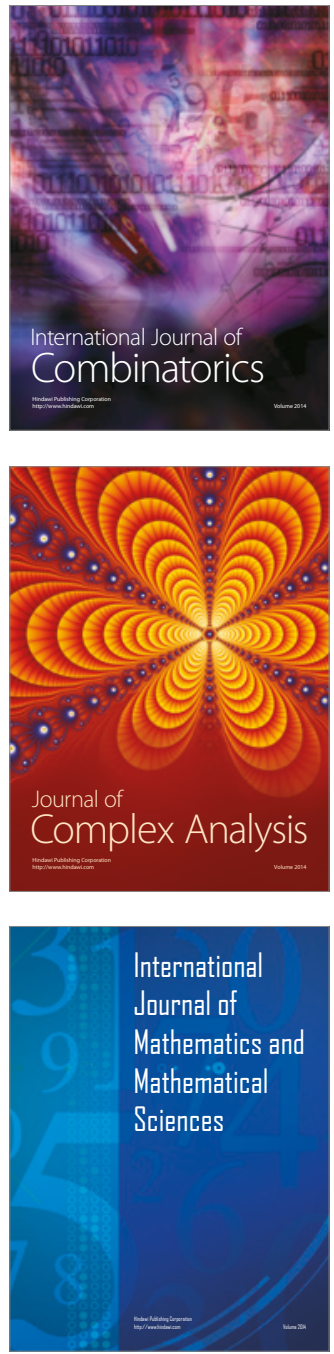
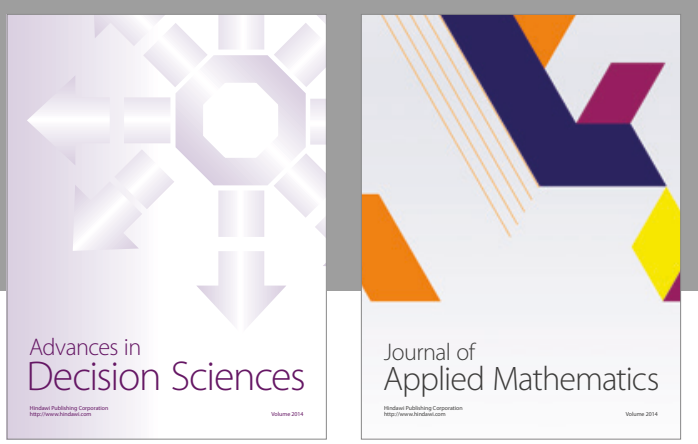

Algebra

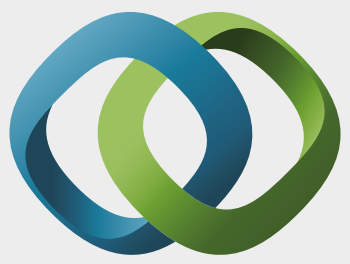

\section{Hindawi}

Submit your manuscripts at

https://www.hindawi.com
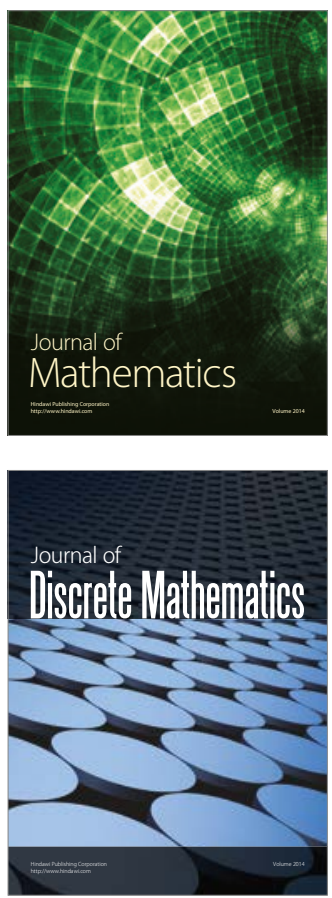

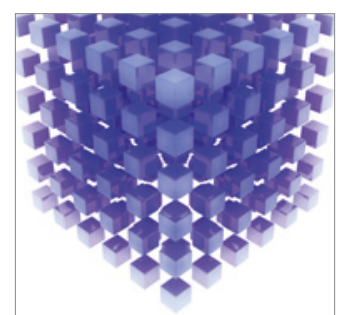

Mathematical Problems in Engineering
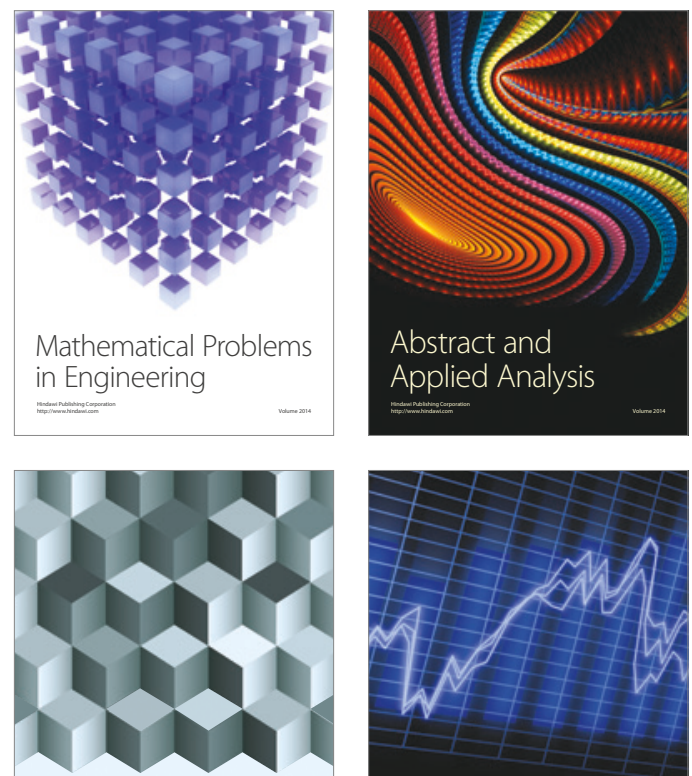

Journal of

Function Spaces

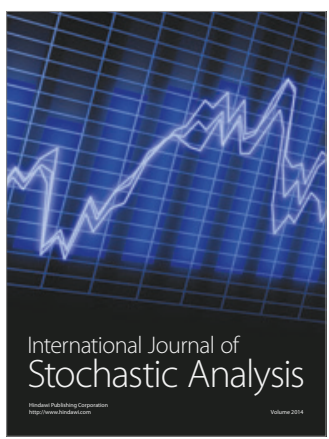

Probability and Statistics
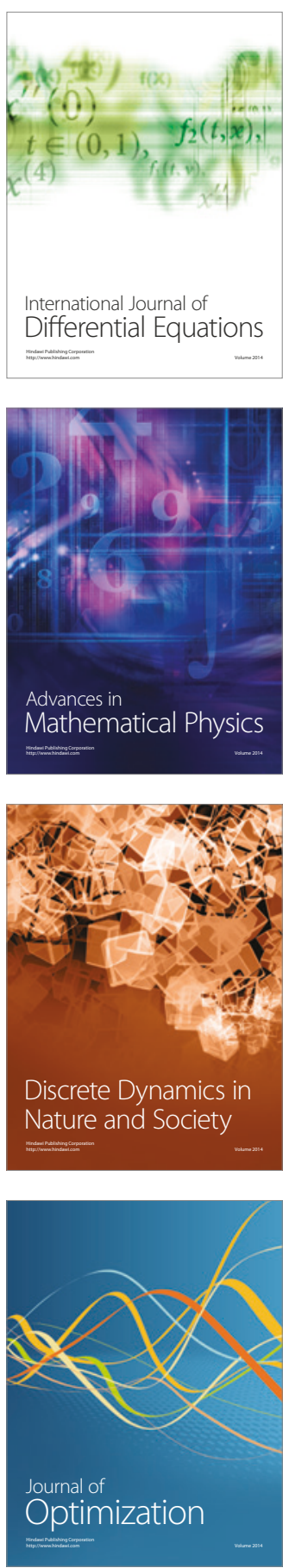